\title{
Challenges of Online Medical Education in Pakistan During COVID-19 Pandemic
}

\author{
Fareeha Farooq ${ }^{2}$, Farooq Azam Rathore ${ }^{1}$ and Sahibzada Nasir Mansoor ${ }^{3}$ \\ ${ }^{1}$ Department of Rehabilitation Medicine, PNS Shifa Hospital, Karachi, Pakistan \\ ${ }^{2}$ Department of Biochemistry, Sir Syed Medical College for Girls, Karachi, Pakistan \\ ${ }^{3}$ Department of Training and Medical Education, Armed Forces Institute of Rehabilitation Medicine, Rawalpindi, Pakistan
}

\begin{abstract}
The novel coronavirus (COVID-19) pandemic has adversely affected economy, social life, and educational services all around the globe. Medical colleges and universities are facing challenges to provide quality education to their students during this prolonged period of lockdown. Technologically advanced countries have systems in place for e-learning and online medical education. This is not the case with most of the low-income countries like Pakistan. Here, we describe the challenges being faced by medical faculty members and students in Pakistan while engaging in online medical education during the COVID-19 pandemic. These include lack of faculty training and institutional support, internet connectivity issues, maintaining student engagement, online assessments, and problems with understanding the unique dynamics of online education. A collaborative approach involving all stakeholders, intuitional support, use of free online training resources, and out of box thinking can help overcome these challenges.
\end{abstract}

Key Words: Analysis, E-learning, Coronavirus, Developing countries, Solutions.

How to cite this article: Farooq F, Rathore FA, Mansoor SN. Challenges of Online Medical Education in Pakistan During COVID-19 Pandemic. J Coll Physicians Surg Pak 2020; 30(JCPSPCR):CR67-CR69 https://doi.org/10.29271/jcpsp.2020.JCPSPCR.CR67.

\section{INTRODUCTION}

The coronavirus (COVID-19) pandemic originated from Wuhan city, China in November 2019 and rapidly spread to more than 200 countries. It has disrupted the economy and social life all around the globe with more than three billion people under a complete or partial lockdown. ${ }^{1}$ Education and teaching has also been adversely affected. Educational institutions including medical colleges and universities have been closed affecting millions of students worldwide. Many institutes have shifted to online education to facilitate students and save loss of time. The technological revolution in the recent years and widespread accessibility and nonstop connectivity, have opened many avenues for distant education and opportunities for learning and exchange of knowledge worldwide. While many developed countries have well-established online and distant- learning programmes in place, this is not the case with most of the medical colleges in the developing countries including Pakistan. The challenges of implementing e-learning in the developing countries are different from the developed world. ${ }^{2}$

Correspondence to: Dr. Farooq Azam Rathore, Department of Rehabilitation Medicine, PNS Shifa Hospital,

DHA II, Karachi, Pakistan

E-mail: farooqrathore@gmail.com

Received: May 19, 2020; Revised: June 15, 2020;

Accepted: June 22, 2020

DOI: https://doi.org/10.29271/jcpsp.2020.JCPSPCR.CR67
We aim to present the challenges being faced by medical students and teaching faculties in the country due to the unprecedented COVID-19 pandemic and offer solutions, based on the current ground realities and resource scarcity in Pakistan.

\section{Challenges and problems with online medical educa- tion:}

A background discussion with faculty members of different medical colleges and medical students in Pakistan revealed that this is a totally new educational experience for most of them. The transition from traditional to online learning has its own challenges. ${ }^{3}$ The majority in Pakistan were not prepared for this sudden transition from in-person teaching to a complete online delivery of educational content in a matter of days without any extensive planning and faculty training. Therefore, both the students and faculties are facing many challenges while engaging in online medical education during the COVID-19 pandemic. The authors highlight some of them and propose possiblesolutions.

- There are 169 medical and dental colleges registered with the Pakistan Medical and Dental College. ${ }^{4}$ Only a few medical universities and colleges were actively conducting online education and teaching sessions for the students before the pandemic. Many colleges do not have a dedicated information technology (IT) department with staff for training of faculty in the use of technology. Poor infrastructure is considered a barrier in medical education, 
specially in the developing countries ${ }^{5}$ and can inhibit teacher's ability to engage with the development or delivery of online learning. ${ }^{6}$ Most of the medical colleges in Pakistan follow the traditional lecture program for teaching. Therefore, most medical teachers and faculty had no previous experience of any online teaching but had no choice but to provide online delivery of lectures and educational content.

- It is incredibly challenging for these faculty members with no prior experience along with lack of training and IT support to engage in effective online medical teaching. Lack of proper training has been identified as an important barrier in implementing e-learning programs. ${ }^{7}$ The quality of teaching in the current circumstances also varies and is not standardised across all institutes. The content delivery is being made via different platforms. Only a few institutes have their own learning management systems with a dedicated IT team to facilitate the faculty. Some institutes are using video conference tools like Zoom and Microsoft Teams to deliver live lectures. Others instruct the faculty to record their lectures using a screen recorder and the lecture is shared on a WhatsApp group or uploaded on a closed Face Book group. In some cases, faculty members were having difficulty in recording lectures from home and had to physically visit their medical institute to record the lecture. A brief online training in recording tools can save these unnecessary visits during COVID-19 pandemic where social distancing is recommended, and unnecessary movements are discouraged.

- Maintaining online learner engagement is challenging even in the technologically advanced countries. ${ }^{8}$ Most faculty members in Pakistan before the pandemic neither had any formal training for online education nor were aware of the dynamics of live online interaction with the students. They find it challenging to engage the students who have a short attention span and are already bored due to the prolonged lockdown. Marking attendance is also a challenge and there are concerns that the students may mark proxy attendance while engaging in other online activities at the same time.

- Faculty members also lack formal training for online assessment such as conducting and marking online exams. They are unaware of the strategies to incorporate quizzes, polls, and mini assignments in the online teaching in order to keep the students engaged and making the lectures more interactive.

- Working from home and maintaining a work-life balance has become particularly difficult for the female faculty during this crisis all around the globe. ${ }^{9}$ In a conservative society like Pakistan, female members of the family have an additional duty of managing their household and taking care of their children, who are also staying at home due to the COVID-19 lockdown. This can become an extra stress for females working and teaching from home during COVID-19 pandemic.

- In addition, there are issues with internet connectivity and low bandwidth to stream video lectures or download large size video lecture files. Students living in rural areas often complain of problems with live streaming of lectures and attending video conferences for lectures.

- Farid and colleagues identified important barriers towards implementation of e-learning in Pakistan. Many of them are applicable to online medical education. These include lack of instructional design, repeated power failures, lack of interest of faculty to adopt a new teaching strategy and sociocultural norms. ${ }^{10}$

- There are no specific guidelines issued for online medical education either by Pakistan Medical and Dental Council or Higher Education Commission of Pakistan to offer a roadmap for transition or implementing e-learning in these challenging times. The current scenario of COVID-19 is an opportunity to implement this teaching and learning methodology in the medical schools and training institutions

\section{The way forward:}

It is important to note that this situation is not unique only to Pakistan. These are challenging times for teachers and educators all around the globe as many of them adjust to the new routines and challenges of teaching their students virtually. ${ }^{8,11}$ It is important that we learn from the experience of others and device our own strategies suited to the local work environment. Pakistani students already have wide exposure to the internet and social media and spend a significant amount of their time online. In a survey of final year medical students from Lahore, Pakistan, $93 \%$ of respondents found e-learning to be effective, with $75 \%$ of the students spending more than $25 \%$ of their study time on e-learning. ${ }^{12}$ Many strategies have been recommended to improve the quality of online teaching and enhancing student engagement. These include providing clear directions at the start of the sessions, interacting with the students instead of just talking, giving breaks, blending both synchronous and asynchronous teaching, introducing gamification and encouraging participation by using polls, breakout rooms, and whiteboards during the sessions. ${ }^{13,14}$ Many free-online courses are available for educators to learn the dynamics of online teaching and create engaging sessions for the students. ${ }^{15}$ Moreover, a number of technology-enhanced assessment techniques are available $^{16}$ and the faculty should make themselves familiar with these technologies. Institutes with established IT and medical education department and experience of successfully managing e-learning before the COVID-19 pandemic should share their experience and provide guidance to those experimenting with e-learning. There is also a need to conduct research to formally document the experiences and challenges being faced by the students and faculties in this pandemic. We need to identify the learning strategies best suited to our academic environment and socio-cultural norms to maximize their impact. There should be close coordination between the major stakeholders of medical education in Pakistan including the Ministry of Health, Pakistan Medical and Dental College, College of Physicians and Surgeons Pakistan, and Higher Education Commission to devise guidelines for delivering e-learning 
during and after the COVID-19 pandemic. Institutions should invest in establishing IT departments, software's, and technology tools to improve their standard of e-learning. In case of financial constraints, low cost options and free open source like Moodle ${ }^{17}$ and others can be considered. ${ }^{18}$

\section{CONCLUSION}

Medical educationists, teachers, administrators, and policy makers in the developing countries should try to convert the adversary of COVID-19 into an opportunity to develop elearning programmes. Hopefully, it will open new avenues in distant-learning in medical education. COVID-19 is a global tragedy, so let us learn our lessons and be better prepared for the future.

\section{CONFLICT OF INTEREST:}

Authors declared no conflict of interest.

\section{AUTHORS' CONTRIBUTION:}

FF, SNM: Critical revision of the manuscript, literature search and final approval.

FAR: Study concept and design, initial draft writing, literature search and final approval.

SNM: Critical revision of the manuscript, literature search and finalapproval.

\section{REFERENCES}

1. Coronavirus: Map reveals 3 billion people are now under lockdown. 26 March 2020. Available from http://www. news.com.au/travel/travel-updates/health-safety/ coronavirus-map-reveals-3-billion-people-are-now-underlockdown/news-story/81a103cfa32da71c18c4a8b62c 43f98b Accessed 4th May 2020.

2. Nawaz A. E-Learning experiences of HEls in advanced states, developing countries and Pakistan. Universal J Educ General Studies 2012; 1(3):72-83.

3. O'Doherty D, Dromey M, Lougheed J, Hannigan A, Last J, McGrath D. Barriers and solutions to online learning in medical education - An integrative review. BMC Med Educ 2018; 18(1):130.

4. Pakistan Medical and Dental Council. Recognized Medical and Dental Colleges. Available from http://www. pmdc.org.pk/MedicalandDentalColleges/tabid/333/Default.a spx Accessed 4th May 2020.

5. Bediang G, Stoll B, Geissbuhler A, Klohn AM, Stuckelberger A, Nko'o S, et al. Computer literacy and Elearning perception in Cameroon: The case of yaounde faculty of medicine and biomedical sciences. BMC Med Educ 2013; 13:57.

6. Dyrbye L, Cumyn A, Day H, Heflin M. A qualitative study of physicians' experiences with online learning in a master's degree program: Benefits, challenges, and proposed solutions. Med Teach 2009; 31(2):e40-e6.

7. Lakbala P. Barriers in implementing E-learning in Hormozgan University of medical sciences. Glob J Health Sci 2015; 8(7):83-92.

8. Cullen MW, Geske JB, Anavekar NS, McAdams JA, Beliveau $\mathrm{ME}$, Ommen SR, et al. Reinvigorating continuing medical education: Meeting the challenges of the digital age. Mayo Clin Proc 2019; 94(12):2501-9.

9. Mahul-Mellier AL. Screams on a zoom call: The theory of homeworking with kids meets reality. Available at http://www.nature.com/articles/d41586-020-01296-7. Accessed 4th May 2020.

10. Farid S, Ahmad R, Niaz IA, Arif M, Shamshirband S, Khattak $M D$. Identification and prioritization of critical issues for the promotion of E-learning in Pakistan. Computers in Human Behavior 2015; 51:161-71.

11. Gewin V. Five tips for moving teaching online as COVID-19 takes hold. Nature 2020; 580(7802):295-6.

12. Maham S, Ghumza F, Shaheryar K, Malik AQ, Kanza A, Huda $\mathrm{N}$, et al. Preference of Use of E-Learning in Medical Education among Undergraduates of King Edward Medical University, Lahore, Pakistan. Ann Community Med Pract 2018; 4(1):1033.

13. Foronda C. Spice up teaching online! Nurse Educ 2014; 39(6):265-6.

14. Parsh B, Gardner P. Teaching a great online class: Six tips for nurse educators. Nursing 2016; 46(2):24-5.

15. Pappas C. The 10 Most Popular Free Online Courses For eLearning Professionals. December 16, 2014 Available at http://elearningindustry.com/10-most-popular-free-online-c ourses-for-elearning-professionals (Accessed $9^{\text {th }}$ May 2020).

16. Khan RA, Jawaid M. Technology Enhanced Assessment (TEA) in COVID 19 pandemic. Pak J Med Sci 2020; 36 (COVID19-S4).

17. Memon AR, Rathore FA. Moodle and online learning in Pakistani Medical Universities: An opportunity worth exploring in higher education and research. J Pak Med Assoc 2018; 68(7):1076-8.

18. Kurt S. Free \& Open Source Learning Management Systems. Educational Technology Available from http://educationaltechnology.net/free-open-source-learning -management-systems/ Accessed 9th May 2020. 